\title{
The management of gynecological complications in long-term survivors after allogeneic hematopoietic cell transplantation-a single-center real-life experience
}

\author{
Łukasz Klasa $^{1}$ (D) Alicja Sadowska-Klasa ${ }^{2}$ (D) $\cdot$ Agnieszka Piekarska $^{2}$ (D) $\cdot$ Dariusz Wydra $^{1}$ (D) Jan Maciej Zaucha ${ }^{2}$ (D)
}

Received: 26 November 2019 / Accepted: 10 April 2020 / Published online: 28 April2020

(C) The Author(s) 2020

\begin{abstract}
In everyday gynecological practice, there is an unmet need to manage survivors after allogeneic hematopoietic cell transplantation (allo-HCT). The major gynecological complications include premature ovarian insufficiency (POI), chronic graft-versushost disease (cGVHD) of the anogenital zone (cGVHDgyn), and secondary neoplasms. Aiming to assess a real-life scale of problems associated with HCT, we performed a detailed analysis of a consecutive series of females after allo-HCT who were referred for a routine gynecological evaluation. The study includes 38 females after allo-HCT in whom gynecological examination with cervical smear and USG were performed, followed by colposcopy according to NCCN guidelines. NIH scoring system was used to classify a grade of cGVHDgyn. The incidence of cGVHD was $71 \%$ whereas GVHDgyn was $29 \%$, including 5 patients with score 3 at the time of diagnosis. The other manifestations (frequently noted) included the skin, mucosa, eyes, and liver. Menopause was diagnosed in $93 \%$ females, and in $81 \%$ of them, POI criteria were fulfilled. Ovarian function resumed in 2 cases. The rate of abnormal cytology was 26\%: 4 ASCUS, 1 AGUS, 1 LSIL, 3 HSIL/ASC-H, and one cytological suspicion of cervical cancer. GVHDgyn was documented in 10 patients, and 6 of them had abnormal cervical cytology. Early topical estrogen therapy led to a significant reduction in vaginal dryness $(p<0.05)$, dyspareunia $(p<0.05)$, and less frequent cGVHDgyn $(p<0.05)$. GVHDgyn develops in about $30 \%$ of long-term allo-HCT survivors. Topical estrogens and hormonal replacement therapy alleviate symptoms and prevent the occurrence of severe consequences of menopause.
\end{abstract}

Keywords Gynecological GVHD $\cdot$ Hematopoietic cell transplantation $\cdot$ POI $\cdot$ Abnormal cytology

\section{Introduction}

The management of gynecological complications in long-term survivors after allogeneic hematopoietic cell transplantation (allo-HCT) remains still an unmet need in daily practice. Although the number of patients with severe symptoms is relatively small, they require special attention and

Łukasz Klasa and Alicja Sadowska-Klasa contributed equally to this work.

Alicja Sadowska-Klasa a.sadowska@gumed.edu.pl

1 Department of Gynecology, Oncological Gynecology and Gynecological Endocrinology, Medical University of Gdansk, Gdansk, Poland

2 Department of Hematology and Transplantology, Medical University of Gdansk, Gdansk, Poland comprehension. Allogeneic HCT affects the gynecological tract by different mechanisms. Gonadotoxicity of pretransplant conditioning regimen leads to premature ovarian insufficiency (POI) in almost all adult women. Besides, the prolonged immunosuppression after transplantation increases the risk of secondary neoplasms $[1,2]$.

However, the most specific and often unrecognized complication is chronic graft-versus-host disease (cGVHD) of the anogenital zone (cGVHDgyn) that was reported for the first time in 1982 [3]. Donor-derived immunocompetent cells can become intolerant to host tissues and recognize them as their targets, leading to the development of a unique complication called graft-versus-host disease (GVHD) [4]. The acute form (aGVHD) that occurs typically up to 100 days post-allo-HCT does not affect the genitourinary tract. However, chronic GVHD which develops more than $50 \%$ of patients can involve every organ and tissue, including genital zone, with the symptomatology often mimicking autoimmune disorders. The diagnosis of cGVHD is based on the clinical 
manifestations and should be confirmed by histopathological examination in case of uncertainty. Chronic GVHD significantly affects the quality of life and remains the leading cause of late non-relapse mortality and morbidity after allo-HCT [5].

Aiming to establish a real-life scale of gynecological problems associated with allo-HCT, we performed a detailed analysis of a series of females after allo-HCT who were referred for a routine gynecological evaluation. We additionally discuss present practical recommendations for gynecological management, supported by the available literature.

\section{Materials and methods}

Our study included 38 female patients who underwent alloHCT at the University Clinical Centre in Gdansk between 2009 and 2018 and were referred in 2018 to the Department of Gynecology. Until 2018, the patients were under the care of local gynecologists. The basic characteristic of the study group is presented in Table 1. During routine visits, gynecological examination with cervical smear and USG were performed. In the case of abnormalities, colposcopy was done according to NCCN guidelines. From 2017, all patients received vaginal, topical estrogen therapy at the discharge from the Transplant Unit. Gynecological problems were categorized into three groups: cGVHD, menopause, and abnormal cervical cytology (Pap smear).

Every patient was evaluated according to the National Institute of Health (NIH) Consensus criteria and scoring system of the genital cGVHD severity [6]. Reported symptoms and clinical signs in gynecological examination classify patient to 0-3 score (Table 2). Subjective symptoms are unspecific and may include dryness, burning, pruritus, dysuria, pain to touch, and dyspareunia leading to sexual dysfunction [7-14]. Particular features of genital cGVHD are lichen planus-like features, lichen sclerosus-like features, vaginal scarring, and clitoral/labial agglutination [6]. Other signs include patchy or generalized erythema, mucosal erosions and fissures, leukokeratosis, labial resorption, labial fusion, fibrinous vaginal adhesion, circumferential fibrous vaginal banding, vaginal shortening, and complete vaginal stenosis [6].

The POI was defined as amenorrhea for at least 4 months with elevated levels of follicle-stimulating hormone $>40 \mathrm{IU} / 1$ in two measurements in 4-6 weeks intervals, in women before 40 years old $[15,16]$.

\section{Statistical analysis}

Categorical variables were expressed as absolute numbers, and respective percentages and the differences between groups were compared using Pearson's $\chi^{2}$ test. Continuous variables were expressed as median values with ranges. A $p$
Table 1 The basic characteristic of the study group

\begin{tabular}{|c|c|}
\hline Median age at HCT (range) & $35.5(16-58)$ \\
\hline \multicolumn{2}{|l|}{ Diagnosis } \\
\hline AML/MDS & $25(66 \%)$ \\
\hline ALL & $8(21 \%)$ \\
\hline Chronic myeloproliferative disorders & $2(5 \%)$ \\
\hline Aplastic anemia & $2(5 \%)$ \\
\hline Hodgkin's disease & $1(2.5 \%)$ \\
\hline Chemotherapy courses prior HCT: & Median (range) \\
\hline $\begin{array}{l}\text { Acute leukemias (intensive } \\
\text { chemotherapy courses induction+ } \\
\text { consolidations) }\end{array}$ & $4(1-8)$ \\
\hline MDS (no cht)/(5-aza)/induction & $2 \mathrm{pts} / 6$ cycles $(2-12) / 1$ (2pts) \\
\hline Chronic myeloproliferative disorders & $\mathrm{TKI} / 1$ induction (blast crisis) \\
\hline Aplastic anemia & No chemotherapy \\
\hline Hodgkin's disease & Prior autoHCT \\
\hline \multicolumn{2}{|l|}{ Type of donor } \\
\hline MSD & $13(34 \%)$ \\
\hline MUD/MMUD & $19(50 \%) / 5(13 \%)$ \\
\hline Haploidentical & $1(2.5 \%)$ \\
\hline \multicolumn{2}{|l|}{ Type of conditioning regimen: } \\
\hline TBI 12Gy-Cy & $9(24 \%)$ \\
\hline $\mathrm{Cy}-\mathrm{Bu} / \mathrm{Bu}-\mathrm{Cy}$ & $20(53 \%)$ \\
\hline FluBu4/FluBu3 & $6(16 \%)$ \\
\hline Cy-ATG & $2(5 \%)$ \\
\hline Other & $1(2.5 \%)$ \\
\hline \multicolumn{2}{|l|}{ Median CD $34 \times 10^{6} / \mathrm{kg}$} \\
\hline PBSC & 6.07 (range 4.27-8.36) \\
\hline BM & 1.2 (range $0.96-1.66$ ) \\
\hline aGVHD before cGVHD & $18(47 \%)$ \\
\hline cGVHD & $27(71 \%)$ \\
\hline Mild/moderate/severe & $13 / 4 / 10$ \\
\hline \multicolumn{2}{|l|}{ Dyspareunia: } \\
\hline GVHDgyn & $6 / 11(54 \%)$ \\
\hline No GVHDgyn & $4 / 27(15 \%)$ \\
\hline \multicolumn{2}{|l|}{ Vaginal dryness: } \\
\hline GVHDgyn & $9 / 11(82 \%)$ \\
\hline No GVHDgyn & $12 / 27(44 \%)$ \\
\hline \multicolumn{2}{|l|}{ Pregnancies/childbirth prior HCT } \\
\hline 0 & $11(29 \%) / 11(29 \%)$ \\
\hline 1 & $7(18 \%) / 10(26 \%)$ \\
\hline 2 & $14(37 \%) / 13(34 \%)$ \\
\hline More & $6(16 \%) / 4(11 \%)$ \\
\hline Menopause prior HCT & $6 / 38(16 \%)$ \\
\hline Menopause post HCT & $30 / 32(94 \%)$ \\
\hline
\end{tabular}

$A M L$ acute myeloid leukemia, $M D S$ myelodysplastic syndrome, $A L L$ acute lymphoblastic leukemia, $M S D$ matched sibling donor, $M U D /$ MMUD matched/mismatched unrelated donor, $P B S C$ peripheral blood stem cells, $B M$ bone marrow, pts patients, $T K I$ tyrosine kinase inhibitors, $H C T$ hematopoietic cell transplantation, 5-aza azacitidie, FluBu fluradabine + busulfan, $C y B u$ cyclophosphamide + busulfan, TBI total body irradiation, $A T G$ anti-thymocyte globulin 
Table 2 Scoring of female genital cGVHD by NIH recommendations

\begin{tabular}{|c|c|c|c|c|}
\hline & Score 0 & Score 1 & Score 2 & Score 3 \\
\hline & No signs & $\begin{array}{l}\text { Mild signs may have symptoms and } \\
\text { discomfort at exam }\end{array}$ & $\begin{array}{l}\text { Moderate signs may have symptoms } \\
\text { and discomfort at exam }\end{array}$ & Severe signs, with or without symptoms \\
\hline Signs & No & $\begin{array}{l}\text { Erythema on mucosal surfaces, } \\
\text { lichen planus-like, lichen sclerosus-like }\end{array}$ & $\begin{array}{l}\text { Erosions in the vulvar mucosa, } \\
\text { fissures in the vulvar folds }\end{array}$ & $\begin{array}{l}\text { Labial fusion, clitoral/labial agglutination, } \\
\text { fibrinous vagina adhesions, } \\
\text { circumferential fibrous vaginal banding, } \\
\text { vaginal shortening, and complete } \\
\text { vaginal stenosis }\end{array}$ \\
\hline
\end{tabular}

value of $<0.05$ was considered statistically significant. All analyses were performed using STATISTICA version 13 (StatSoft, Inc.).

\section{Ethical approval}

This study was performed in accordance with the latest version of the Declaration of Helsinki and received the approval of the Independent Bioethics Committee of the Medical University of Gdansk. All patients signed informed consent.

\section{Results}

Chronic GVHD In the study group, 71\% (27/38) of referred patients suffered from cGVHD at some location (Fig. 1) with the most common presentation in the skin (18/27), liver (18/ $27)$, mucosa (17/27), and eyes (12/27). There was a statistically significant positive correlation between GVHDgyn and skin involvement $(p<0.01)$. The incidence of GVHDgyn was $29 \%$ (11 out of 38 patients) in all with cGVHD in other locations. Four patients had score 1, two score 2, and the rest (45\%) score 3, which defines the severe form of cGVHD according to the NIH classification. There was one patient with partial and one with the complete vaginal stenosis. In two cases, circumferential fibrous bandings in vagina were found. We had a partial success in treatment of the patient with incomplete vaginal stenosis. Using concomitant surgery and steroid treatment, we managed to enlarge and lengthen vagina up to $8 \mathrm{~cm}$ enabling the patient to resume intercourse. We observed improvement in patients with milder forms of GVHD after treatment (Fig. 1), however not in a patient with complete vaginal stenosis.

Menopause Six women experienced already menopause before hematological treatment. From the remaining 32 patients (median age 33, range 16-47), menopause was diagnosed in $30(94 \%)$ females. In $81 \%$ of them, the age at the time of menopause was below 40 . Ovarian function resumed in 2 cases: in the patient with acute lymphoblastic lymphoma transplanted at the age of 17 , and in one who underwent allo-HCT at the age of 16 for aplastic anemia. Fifty-five percent of women suffered from vaginal dryness, and $23 \%$ reported dyspareunia during the first gynecological visit. Twenty-one patients (55\%) were sexually inactive after alloHCT, due to gynecological symptoms (7 patients), a fear caused by inadequate information or permission ( 6 ones), a lack of a sexual partner (4 ones), and no prior sexual experience (4 ones). Seventeen patients received local estrogens at the discharge from the transplantation department. A significant reduction in vaginal dryness $(p<0.05)$ and dyspareunia $(p<0.05)$ as well as less frequent cGVHDgyn $(p<0.05)$ were observed in women with early topical estrogen therapy.

Abnormal cytology We found abnormal cytology in 10 women (26\%): 4 ASCUS (atypical squamous cells of undetermined significance), 1 AGUS (atypical glandular cells of undetermined significance), 1 LSIL (low-grade squamous intraepithelial lesion), $3 \mathrm{HSIL} / \mathrm{ASC}-\mathrm{H}$ (high-grade squamous intraepithelial lesion/ atypical squamous cells cannot exclude HSIL), and one cytological suspicion of cervical cancer. None of the patients had the HPV status checked. There were indications for the biopsy in 5 cases (Table 3). In the remaining 5 patients with abnormal cytology (LSIL, ASCUS) colposcopy revealed no pathological findings requiring a biopsy. In the histopathological examination, in case of uncertainty, immunohistochemical p16 staining was evaluated to confirm HPV infection. In 6 out of 10 patients with abnormal cervical cytology, the clinical signs of GVHDgyn were documented. With a median follow-up of 2.5 years ( $0.5-11$ years), there was no case of cervical cancer documented in our group.

\section{Discussion}

Our study shows that gynecological care provided by the local practitioners to the long-term allo-HCT female survivors was rather inadequate for the following findings. Firstly, despite the high incidence (71\%) of cGVHD in 38 patients referred to our department, only $40 \%$ of them received any local treatment for gynecological symptoms. Secondly, $45 \%$ of patients 

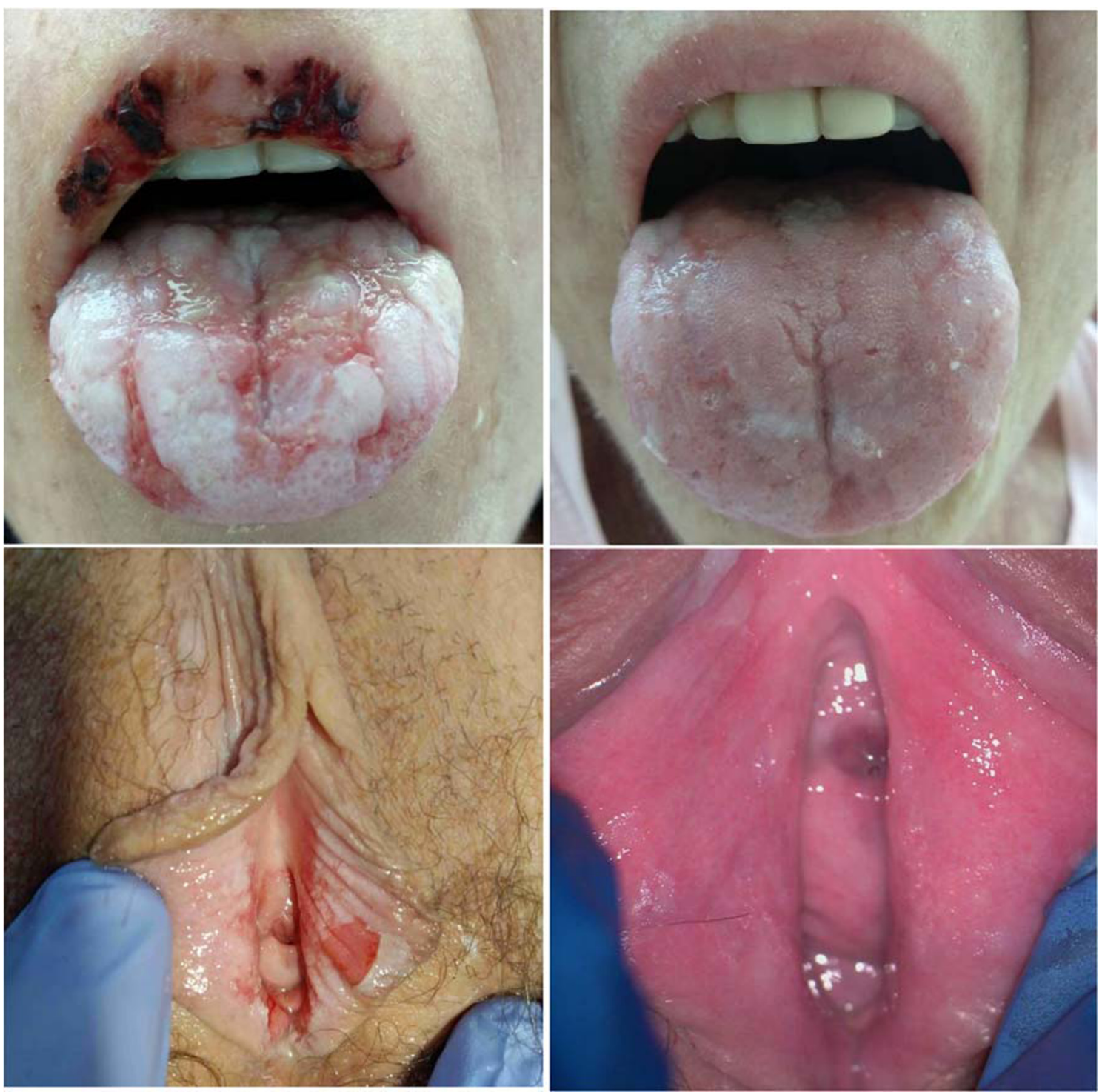

Fig. 1 Simultaneous changes during cGVHD in the same patient: mucosal involvement and cGVHDgyn at the time of diagnosis (left side) and after 2 weeks of the treatment (right side)

had the highest (score 3) for female genital cGVHD according to the NIH recommendations, and even two patients were documented with partial or complete vaginal stenosis.

The higher cGVHDgyn morbidity in our group than reported by others $[7,14,17,18]$ (ranging between 25 and $60 \%$ depending on the criteria used) may result from some patient preselection since patients with gynecological symptoms were more likely to visit a dedicated gynecologist. High morbidity may also result from the peripheral blood stem cells used as a graft source in our patients, which is known to increase the risk of cGVHDgyn comparing with bone marrow transplantation grafts $[7,14]$. Initially, morbidity rate for cGVHDgyn was estimated at only $3 \%$ [14]. The reason for such significant discrepancies was the lack of standard gynecological care after allo-HCT in many places, inducing our center, and the fact that patients rarely report symptoms at the time of routine post-transplant visits.
The median time of developing GVHDgyn after allo-HCT reported in the literature is $7-10$ months $[7,14,18]$. In about $70 \%$ of patients, signs affect only the vulva, and in $30 \%$ both vulva and vagina, and vaginal symptoms usually appear after vulvar $[14,18]$. We could not verify the time of GVHDgyn development in our group, due to suboptimal gynecological care in the past; however, from 2018 prospective analysis has been launched in our center. Chronic GVHDgyn is almost always associated with cGVHD manifestation in other organs such as the skin, mouth, liver, or gastrointestinal tract [7, 14, 18]. Zantomio et al. reported even $90 \%$ probability of GVHDgyn coexistence with other organ involvement, most often the mouth and skin [7]. The positive correlation between gynecological and skin manifestation of GVHD documented in our group corroborates this notion. Interestingly we found no statistically significant correlation between GVHDgyn and 
Table 3 Cytological and histopathological results in our observation

\begin{tabular}{llll}
\hline Cytology (Bethesda system) & Histopathology (biopsy) & Further management & Conclusion \\
\hline $\begin{array}{l}\text { Cytological suspicion } \\
\text { of cervical cancer }\end{array}$ & cGVHD, no dysplasia & cGVHD topical treatment (steroids) & False positive cytology \\
ASC-H & CIN3(cervical intraepithelial neoplasia) & Cervical conization (CIN3 in removed tissue) & True positive cytology \\
ASC-H & $\begin{array}{c}\text { No dysplasia (lichen sclerosus in } \\
\text { the biopsy from the vulva) }\end{array}$ & $\begin{array}{l}\text { Treatment of lichen sclerosus of the vulva (steroids) } \\
\text { No dysplasia }\end{array}$ & False positive cytology \\
HSIL & $\begin{array}{c}\text { Suspicion of CIN3 in cervical } \\
\text { canal (insufficient material) }\end{array}$ & Cervical conization (no dysplasia in removed tissue) & False positive cytology \\
AGUS & & & False positive cytology \\
& & & \\
\hline
\end{tabular}

mucosal manifestation. Although an isolated gynecological manifestation of GVHD is possible, we did not observe isolated cases in our study group [15]. The most common other manifestations of cGVHD in our series were also the skin, mouth, and liver. The National Institute of Health recommends gynecological examination in every woman after allo-HCT, especially when signs of cGVHD occur in the mouth mucosa, showing the strongest correlation with GVHDgyn [6]. Topical estrogen therapy should be initiated early after allo-HCT in all patients (even in those using hormonal replacement therapy; HRT) [7]. That may not prevent from GVHDgyn but minimalize menopausal symptoms mimicking GVHD and therefore helps to diagnose GVHD in an early stage. Due to a high probability of hypoestrogenism, all women after allo-HCT were advised to apply topical estrogen in the form of creams or vaginal globules twice a week from the time of discharge from the Transplant Unit. In our series, only $45 \%$ of patients complied with this recommendation. They presented, however, with fewer symptoms which indicate the protective role of local estrogen therapy in the prevention of dryness, dyspareunia, as well as may have some impact on GVHDgyn.

Topical glucocorticosteroids serve as an essential component in the treatment of GVHDgyn [7, 10, 14, 18]. Only some patients in our group received such treatment. Now we advise high vaginal application of hydrocortisone acetate $10 \mathrm{mg} / \mathrm{g}$ cream $1 \mathrm{~g}$ daily, for 4-6 weeks in GVHDgyn and local calcineurin inhibitors in case of more superficial lesions [7].

The risk of ovarian failure after allo-HCT depends mainly on the age at transplantation and conditioning regimen [1-4] (Table 4). High doses of alkylating agents and TBI irreversibly damage hormonal and reproductive function of the ovary in the majority of females $[2,4]$. In less than $5 \%$ of women after allo-HCT, the ovarian function returns, but often for a short period, what was also observed in our study. In our group, resumption of ovarian function occurred solely in the youngest $(<20)$ allo-HCT recipients. According to Chiodi et al., age at allo-HCT and a dose of TBI have the strongest impact on the menopause. The cumulative probability of menstrual cycle resumption in patients aged $<20,20-30$, and $>30$ years old was $88 \%, 27 \%$, and only $3 \%$, respectively. In turn, in females who received TBI and cyclophosphamide, the probability of regaining the ovarian function in the same ranges was $84 \%, 20 \%$, and $0 \%$, respectively [22]. Patients with a recovery of menstruation cycles are anyway at the high risk of infertility and early menopause [22]. Options of preservation and restoration of fertility can be categorized as wellestablished, debatable, and experimental. Embryo and egg freezing are well-established and effective options. Debatable ones include ovarian protection techniques such as gonadotropin-releasing hormone ( $\mathrm{GnRH})$ analogs, transposition of ovaries, or gonadal shields before radiation [19]. Reimplantation of cryopreserved ovarian tissue remains still experimental due to the unacceptable risk of potential recurrence of hematological malignancies [23]. Women with POI should be advised hormonal therapy of menopause (HTM) until the age of natural menopause if contraindications are excluded. There is no evident data on the optimal regimen, doses, and a route of sex hormones in POI [16]. The classical HTM or combined contraceptive pills may be used as replacement therapies, although HTM seems to have a better influence on the cardiovascular system and bone health [16]. Hormonal replacement therapy should be started early after transplantation in every woman after allo-HCT with POI under age of 40, even if asymptomatic [7, 14, 17, 24]. After 40 years old, HTM is recommended for patients with menopausal symptoms. The therapy should be continued until the age of natural menopause.

A history of thromboembolic episodes is one of the contraindications of HTM. In some patients, a deep vein thrombosis occurs as a complication of the central catheter. It is a transient risk factor and in the absence of other contraindications should not be the reason for depriving of HTM. The transdermal route of estrogens in POI is probably the best option [14-16]. As estrogens avoid the first pass through the liver, the lower impact on coagulation cascade is observed [16]. Large observational studies have proved a lower risk of venous thromboembolism, and a stroke when a transdermal route of estrogen administration is used instead of an oral route. Moreover, the risk of thrombotic complications was not increased when compared with the agematched controls in natural menopause [16]. 
Table 4 A risk of therapy-induced gonadotoxicity and POI in young woman with hematological malignancies [19-21]

\begin{tabular}{|c|c|c|c|c|}
\hline $\begin{array}{l}\text { Risk of } \\
\text { gonadotoxicity }\end{array}$ & $\begin{array}{l}\text { Acute lymphoblastic } \\
\text { leukemia (ALL) }\end{array}$ & $\begin{array}{l}\text { Acute myeloid } \\
\text { leukemia (AML) }\end{array}$ & Non-Hodgkin lymphoma (NHL) & Hodgkin lymphoma \\
\hline Medium risk & \multicolumn{2}{|l|}{ Standard protocols } & CHOP & ABVD \\
\hline High risk & \multicolumn{2}{|c|}{ High dose of cyclophosphamide-multiple drug regimens } & $\begin{array}{l}\text { Radiotherapy: pelvis or abdomen } \\
\text { Second line chemo: ICE, } \\
\text { auto-HCT without TBI }\end{array}$ & $\begin{array}{l}\text { Radiotherapy: pelvis or abdomen } \\
\text { Chemotherapy: } \\
\text { MOPP, BEACOPP } \\
\text { Auto-HCT without TBI }\end{array}$ \\
\hline Very high risk & \multicolumn{4}{|c|}{ Myeloablative conditioning regimens with TBI and/or high dose of alkylating agents preceding autologous or allogeneic HCT } \\
\hline Unknown impact & $\begin{array}{l}\text { Novel agents } \\
\text { Blinatumomab } \\
\text { Inotuzumab } \\
\text { CAR-T cells }\end{array}$ & $\begin{array}{l}\text { Novel agents } \\
\text { Gemtuzumab ozogamicin } \\
\text { FLT3 inhibitors }\end{array}$ & $\begin{array}{l}\text { Novel agents } \\
\text { ALK inhibitors } \\
\text { BiTEs } \\
\text { CAR-T cells }\end{array}$ & $\begin{array}{l}\text { Novel agents } \\
\text { Brentuximab vedotin } \\
\text { Checkpoint inhibitors }\end{array}$ \\
\hline
\end{tabular}

A hepatic form of cGVHD and toxic liver damage poses another problem. In benign forms of liver impairment, the transdermal route of hormone administration is a safe option due to avoidance of liver circulation. In overweight or obese patients, percutaneous HTM administration is associated with a lower risk of thromboembolism in comparison with an oral route [15]. In our study group, no thrombotic events or hepatic toxicity of HTM was observed.

In our group, we did not observe secondary neoplasms which are well known, significant long-term complications of allo-HCT, and are responsible for $10 \%$ of late deaths [1, 25]. A large multicenter European study estimated the risk of secondary neoplasms to $11.5 \%$ after 15 years from allo-HCT, and the most common sites include the skin, oral cavity, larynx, cervix, and endometrium [26]. A prolonged immunosuppressive therapy in cGVHD leads to impaired T and B lymphocyte responses, leading to reactivation of latent HPV infections [2, 26, 27]. For this reason, cGVHD at any location promotes the process of cervical intraepithelial neoplasia [27, 28]. Moreover, a gynecological form of GVHD is an independent risk factor of HSIL [2]. The incidence of abnormal cytology in patients after allo-HCT reaches up to $40-70 \%$ according to different authors, which is many times higher than in a healthy population $(4 \%)[2,10,14,17,18,27]$. We present similar data in our study. However, verification of abnormal cytology showed a high percentage of false positive cytology related to GVHDgyn, not yet reported in the literature. This observation indicates difficulties in cervical cancer prevention in allo-HCT recipients and a need for experienced gynecological assessment. This issue requires further investigation.

Complete vaginal stenosis in GVHDgyn diagnosed in one patient not only impairs the quality of life but also makes Pap smear difficult or even impossible to perform. Generally, cytology is recommended to be performed once a year in women after allo-HCT [2, 7, 10, 12, 14, 17, 27]. Histopathological verification should take place in centers experienced in recognizing cGVHD. Vaccination against HPV is advised in previously unvaccinated women $<26$ years old [17, 27-29]. The immunization program should start 6-12 months after transplantation $[17,28,29]$. According to the guidelines of Infectious Diseases Working Group of Polish Adult Leukemia Group (PALG), three doses are recommended with 2-month intervals, although data on the immunogenicity of these vaccines in patients after allo-HCT is missing [30]. Older women who have not been vaccinated or patients vaccinated before can also benefit from additional vaccination after transplantation [29].

\section{Conclusions}

The regular and multidisciplinary follow-up, including gynecological care, is essential to prevent serious complications after allo-HCT. Premature ovarian failure, irreversible in most cases, is one of the consequences of this treatment. The attending physician's task is to make patients aware of the gonadotoxic effects of therapy and discuss fertilitypreserving methods. Topical estrogens and HRT give relief of unpleasant symptoms and reduce the risk of severe complications of menopause in the bones, heart, or central nervous system. Chronic GVHD may also involve the urogenital zone. Since the symptoms of GVHDgyn are similar to those resulting from hypoestrogenism, patients should be encouraged to report any signs and to visit a gynecologist regularly. Only early diagnosis and prompt treatment of mild and moderate forms of GVHDgyn allow avoiding the most severe cases of complete vaginal stenosis with very limited therapeutic options left. Previous chemo- and radiotherapy, but mainly prolonged immunosuppressive therapy and GVHDgyn, increase the risk of secondary neoplasms significantly. Therefore, long-term allo-HCT survivors should remain under meticulous antineoplastic surveillance. 


\section{Compliance with ethical standards}

This study was performed in accordance with the latest version of the Declaration of Helsinki and received the approval of the Independent Bioethics Committee of the Medical University of Gdansk. All patients signed informed consent.

Conflict of interest The authors declare that they have no conflict of interest.

Open Access This article is licensed under a Creative Commons Attribution 4.0 International License, which permits use, sharing, adaptation, distribution and reproduction in any medium or format, as long as you give appropriate credit to the original author(s) and the source, provide a link to the Creative Commons licence, and indicate if changes were made. The images or other third party material in this article are included in the article's Creative Commons licence, unless indicated otherwise in a credit line to the material. If material is not included in the article's Creative Commons licence and your intended use is not permitted by statutory regulation or exceeds the permitted use, you will need to obtain permission directly from the copyright holder. To view a copy of this licence, visit http://creativecommons.org/licenses/by/4.0/.

\section{References}

1. Lowe T, Bhatia S, Somlo G (2007) Second malignancies after allogeneic hematopoietic cell transplantation. Biol Blood Marrow Transplant 13(10):1121-1134

2. Wang Y, Brinch L, Jebsen P, Tanbo T, Kirschner R (2012) A clinical study of cervical dysplasia in long-term survivors of allogeneic stem cell transplantation. Biol Blood Marrow Transplant 18(5): $747-753$

3. Corson SL, Sullivan K, Batzer F, August C, Storb R, Thomas ED (1982) Gynecologic manifestations of chronic graft-versus-host disease. Obstet Gynecol 60(4):488-492

4. Ferrara JLM, Levine JE, Reddy P, Holler E (2009) Graft-versushost disease. Lancet (London, England) 373(9674):1550-1561

5. Lee SJ (2017) Classification systems for chronic graft-versus-host disease. Blood. 129(1):30-37

6. Jagasia MH, Greinix HT, Arora M, Williams KM, Wolff D, Cowen EW et al (2015) National Institutes of Health Consensus Development Project on Criteria for Clinical Trials in Chronic Graft-versus-Host Disease: I. The 2014 Diagnosis and Staging Working Group Report. Biol Blood Marrow Transplant 21(3): 389-401.e1

7. Zantomio D, Grigg AP, MacGregor L, Panek-Hudson Y, Szer J, Ayton R (2006) Female genital tract graft-versus-host disease: incidence, risk factors and recommendations for management. Bone Marrow Transplant 38(8):567-572

8. Smith Knutsson E, Björk Y, Broman A-K, Helström L, Levin Jakobsen A-M, Nilsson O, Sundfeldt K, Brune M (2014) Genital chronic graft-versus-host disease in females: a cross-sectional study. Biol Blood Marrow Transplant 20(6):806-811

9. Chung CP, Sargent RE, Chung NT, Lacey JV, Wakabayashi MT (2016) Graft-versus-host disease-associated vulvovaginal symptoms after bone marrow transplantation. Biol Blood Marrow Transplant 22(2):378-379

10. Andrea Ciavattini NC (2015) Female genital tract chronic graftversus-host disease: review of the literature. Anticancer Res 12: $13-18$

11. Spinelli S, Chiodi S, Costantini S, Van Lint MT, Raiola AM, Ravera $\mathrm{G}$ et al (2003) Female genital tract graft-versus-host disease following allogeneic bone marrow transplantation. Haematologica. 88(10):1163-1168

12. Hirsch P, Leclerc M, Rybojad M, Petropoulou AD, Robin M, Ribaud P et al (2012) Female genital chronic graft-versus-host disease. Transp J 93(12):1265-1269

13. Scrivani C, Merideth MA, Klepac Pulanic T, Pavletic S, Childs RW, Hsieh MM, Stratton P (2017) Early diagnosis of labial fusion in women after allogeneic hematopoietic cell transplant enables outpatient treatment. J Low Genit Tract Dis 21(2): $157-160$

14. Frey Tirri B, Häusermann P, Bertz H, Greinix H, Lawitschka A, Schwarze C-P, Wolff D, Halter JP, Dörfler D, Moffat R (2015) Clinical guidelines for gynecologic care after hematopoietic SCT. Report from the international consensus project on clinical practice in chronic GVHD. Bone Marrow Transplant 50(1):3-9

15. Hamoda H, Panay N, Arya R, Savvas M (2016) The British Menopause Society \& Women's Health Concern 2016 recommendations on hormone replacement therapy in menopausal women. Post Reprod Heal 22(4):165-183

16. Hamoda H (2017) The British Menopause Society and Women's Health Concern recommendations on the management of women with premature ovarian insufficiency. Post Reprod Heal 23(1):2235

17. Brennan A, Hickey M (2017) Gynaecological care after stem cell transplant: an overview. Maturitas. 105:30-32

18. Kornik RI, Rustagi AS (2017) Vulvovaginal graft-versus-host disease. Obstet Gynecol Clin N Am 44(3):475-492

19. Salama M, Anazodo A, Woodruff TK. Preserving fertility in female patients with hematological malignancies : a multidisciplinary oncofertility approach . 2019;

20. Blumenfeld Z (2012) Chemotherapy and fertility. Best Pract Res Clin Obstet Gynaecol 26(3):379-390

21. Bedoschi G, Navarro PA, Oktay K (2016) Chemotherapy-induced damage to ovary : mechanisms and clinical impact. Future Oncol 12:2333-2344

22. Chiodi S, Spinelli S, Bruzzi P, Anserini P, Di Grazia C, Bacigalupo A (2016) Menstrual patterns, fertility and main pregnancy outcomes after allogeneic haematopoietic stem cell transplantation. J Obstet Gynaecol (Lahore) 36(6):783-788

23. Fehm ANST, Goeckenjan KBM, Henes PWM, Fey JHMF (2018) Practical recommendations for fertility preservation in women by the Ferti PROTEKT network . Part I : Indications for fertility preservation. Arch Gynecol Obstet 297(1):241-255

24. Piccioni P, Scirpa P, D’Emilio I, Sora F, Scarciglia M, Laurenti L, de Matteis S, Sica S, Leone G, Chiusolo P (2004) Hormonal replacement therapy after stem cell transplantation. Maturitas. 49(4):327333

25. Wingard JR, Majhail NS, Brazauskas R, Wang Z, Sobocinski KA, Jacobsohn D, Sorror ML, Horowitz MM, Bolwell B, Rizzo JD, Socié G (2011) Long-term survival and late deaths after allogeneic hematopoietic cell transplantation. J Clin Oncol 29(16):2230-2239

26. Kolb HJ, Socié G, Duell T, Van Lint MT, Tichelli A, Apperley JF et al (1999) Malignant neoplasms in long-term survivors of bone marrow transplantation. Ann Intern Med 131(10):738744

27. Savani BN, Stratton P, Shenoy A, Kozanas E, Goodman S, Barrett AJ (2008) Increased risk of cervical dysplasia in long-term survivors of allogeneic stem cell transplantation-implications for screening and HPV vaccination. Biol Blood Marrow Transplant 14(9):1072-1075

28. Savani BN, Goodman S, Johnbarrett A (2009) Can routine posttransplant HPV vaccination prevent commonly occurring epithelial cancers after allogeneic stem cell transplantation? Clin Cancer Res 15(7):2219-2221 
29. Tedeschi SK, Savani BN, Jagasia M, Engelhardt B, Anasetti C, Barrett AJ, Lee S (2010) Time to consider HPV vaccination after allogeneic stem cell transplantation. Biol Blood Marrow Transplant 16(8):1033-1036

30. Piekarska A, Giebel S, Basak GW, Dybko J, Hałaburda K, Hus I, Karakulska-Prystupiuk E, Jakubas B, Mensah-Glanowska P, Rzepecki P, Wierzbowska A, Gil L (2017) Szczepienia ochronne u chorych dorosłych po przeszczepieniu komórek krwiotwórczych - zalecenia sekcji do spraw zakażeń PALG. Acta Haematol Pol 48(1):1-9

Publisher's note Springer Nature remains neutral with regard to jurisdictional claims in published maps and institutional affiliations. 